\title{
MRI Coil Type
}

National Cancer Institute

\section{Source}

National Cancer Institute. MRI Coil Type. NCI Thesaurus. Code C116119.

The classification of the coil that is used in an magnetic resonance imaging procedure.

Usually refers to the anatomical location for where the coil is placed such as head, body or breast. 